Research, part of a Special Feature on Exploring Opportunities for Advancing Collaborative Adaptive Management (CAM): Integrating Experience and Practice

\title{
Practitioner Perceptions of Adaptive Management Implementation in the United States
}

\author{
Melinda Harm Benson $^{1}$ and Asako B. Stone ${ }^{2}$
}

ABSTRACT. Adaptive management is a growing trend within environment and natural resource management efforts in the United States. While many proponents of adaptive management emphasize the need for collaborative, iterative governance processes to facilitate adaptive management, legal scholars note that current legal requirements and processes in the United States often make it difficult to provide the necessary institutional support and flexibility for successful adaptive management implementation. Our research explores this potential disconnect between adaptive management theory and practice by interviewing practitioners in the field. We conducted a survey of individuals associated with the Collaborative Adaptive Management Network (CAMNet), a nongovernmental organization that promotes adaptive management and facilitates in its implementation. The survey was sent via email to the 144 participants who attended CAMNet Rendezvous during 2007-2011 and yielded 48 responses. We found that practitioners do feel hampered by legal and institutional constraints: $>70 \%$ of respondents not only believed that constraints exist, they could specifically name one or more examples of a legal constraint on their work implementing adaptive management. At the same time, we found that practitioners are generally optimistic about the potential for institutional reform.

Key Words: adaptive management; Collaborative Adaptive Management Network; natural resource management; organizational change; practitioners

\section{INTRODUCTION}

Adaptive management (AM) is an emerging trend among natural resource decision-makers, reflecting a willingness to test our assumptions about social-ecological systems (SESs) in order to adapt and learn. This approach has the potential to shift the current environmental governance paradigm by fostering a new relationship between environmental science and social institutions, a relationship that embraces uncertainty and possesses the flexibility necessary to incorporate that uncertainty into management actions involving natural systems. Examples of recent attempts to incorporate AM in the United States include the U.S. Department of Interior's development of a technical guide for AM implementation (Williams et al. 2009), landowner based habitat conservation planning under the Endangered Species Act (Ruhl 2005), and the compensatory wetlands mitigation protection program under the Clean Water Act (U.S. Army Corps of Engineers 2002).

Our research explores one element of the bridge between theory and practice: the experiences of AM practitioners in the field. Many, if not most, of these practitioners are trained in the natural sciences, and, not surprisingly, much of the research related to AM takes place within the disciplines of ecology, conservation biology, and other natural sciences. This scholarship is placing increasing emphasis on the natural world as a suite of complex systems and on an acknowledgement of the adaptive cycle as a basis for understanding the dynamics of ecosystems (Walters 2002).
These nonequilibrium systems theories embrace the complexity, uncertainty, and instability associated with both social and ecological systems processes (Gunderson and Holling 2002, Folke et al. 2005). Adaptive management is seen as a key strategy for fostering resilience, and emerging from the literature are increasingly robust engagements of AM, both in terms of theoretical advancements (e.g., Lee 1999, Salafsky et al. 2002, McCarthy and Possingham 2007) and practical applications (e.g., Berkes and Seixas 2005, King and Brown 2006, Allan et al. 2008, Brugnach et al. 2008, Nie and Schultz 2012).

This new view of SESs is now being incorporated into federal agencies and other natural resource management arenas that are defined by legal and regulatory frameworks. The legal scholarship on AM that examines this trend reflects two major areas of emphasis. First, there is an acknowledgment that virtually all of the efforts to integrate AM strategies to date reflect attempts to fit AM within existing legal mandates and protocols. While existing management mandates are usually sufficiently vague to encompass AM approaches, "the disconnect between $\mathrm{AM}$ in practice and $\mathrm{AM}$ in law is quite palpable... No other principle of natural resources law has so deeply permeated the practice on the basis of so little mention in law" (Ruhl 2008:11-3). As a result, AM is being thrown like a blanket on top of existing authorizations and requirements, with little attention to how practitioners balance this new mandate in relation to other legal and institutional requirements. Critics of AM have argued that without more 
specific legal grounding, AM provides agencies with an unreasonable amount of discretion (Doremus 2002, Houck 2009). Similarly, AM proponents have cautioned against lax standards that would, in essence, create a situation in which agencies use it as "rhetorical cover for requests for blanket preauthorization to reverse or revise policies should the agency later decide to change its mind" (Karkkainen 2004:356).

The second shared observation among legal scholars is that current legal and regulatory requirements do not generally support the iterative processes required by AM (Thrower 2006, Ruhl 2008, Craig 2010). For example, the National Environmental Policy Act (NEPA) is the major federal law that requires agencies to take a "hard look" at the environmental impacts of proposed agency action. NEPA makes a number of assumptions that are at odds with AM, including the assumption that there is a single, final "agency action" rather than a series of iterative processes, and that resource managers already have the knowledge of natural systems needed to assess environmental impacts (Benson and Garmestani 2011). Several law review articles have highlighted the challenges associated with engaging in AM (Angelo 2009, Benson 2010a, b, Zellmer and Gunderson 2008, Susskind et al. 2010).

It therefore appears that although ecology tells us that collaboratively based, iterative processes are needed to promote flexibility and facilitate adaptation (e.g., Gunderson and Light 2006), legal scholars note that this stands in opposition to most legal requirements and processes, in which enforceable standards are viewed as preferable to open-ended guidance (Nie 2008). This disconnect has both practical and theoretical importance. From a practical point of view, AM methodologies are of limited value unless they can be employed within the highly complex and overlapping regulatory frameworks that often exist in developed countries such as the United States. From a theoretical perspective, experiments in applying AM within explicit legal and regulatory contexts could allow the refinement of AM models and methodologies.

Scholarship regarding how institutions facilitate and constrain successful employment of AM methodologies tends to emphasize the importance of polycentric governance, collaborative processes, the role of social learning, and issues of scale (Bodin et al. 2006, Stringer et al. 2006, Folke et al. 2007, Pahl-Wostl 2007, Pahl-Wostl et al. 2007, Brugnach et al. 2008, Raadgever et al. 2008). The subset of this literature that specifically addresses AM implementation in the United States emphasizes the need for a more explicit commitment to AM methodologies (Moir and Block 2001, Stankey et al. 2003, Benson 2010a,b). Jacobson et al. (2006) looked at barriers to AM implementation by surveying the 90 staff members of the Florida Fish and Wildlife Conservation Commission using a questionnaire that identified 47 potential barriers to the use of AM. Although legal and regulatory requirements were not listed explicitly, related issues regarding management flexibility and availability of agency resources were included among the categories on logistical and institutional barriers. Their survey revealed that logistical issues were the most problematic of all barriers, specifically citing lack of agency resources and the time-consuming nature of AM protocols (Jacobson et al. 2006). Similarly, Butler and Koontz (2005) surveyed 345 U.S. Forest Service managers regarding their experiences implementing the agency's ecosystem management objectives, of which AM is one component (Grumbine 1994). Their results established that managers viewed $\mathrm{AM}$ as the most difficult element of ecosystem management to implement (Butler and Koontz 2005). Among the reasons for this, managers cited the significant institutional changes required, the immense costs of monitoring, and the lack of public and political support. One interviewee was quoted as stating: "Adaptive management happens, but is a reach for the agency. We don't have all the mechanisms in place to do it well, and there are legal, logistical, contractual and social constraints" (Butler and Koontz 2005:146). Butler and Koontz's (2005:148) conclusions emphasize that "continued attention and inquiry is needed to generate insights for academics and professionals involved in ecosystem management, from theory to practice." Our research builds upon this work by asking questions specifically related to legal and institutional influences on AM implementation.

\section{METHODS}

Our review of the relevant literature reveals the need to gain a better understanding of the impact of legal and institutional frameworks on AM implementation. By legal, we mean the statutory and regulatory mandates that both drive and influence many AM projects (e.g., species protection, environmental assessment compliance). By institutional, we mean other aspects of management design (e.g., funding priorities, monitoring protocols) that may not necessarily reflect specific legal requirements but are nevertheless an important part of the overall decision-making and management structure in which AM operates. Our research adds to the literature by investigating how AM practitioners experience the tension between the theoretical articulations of AM methodologies and the actual implementation of AM strategies within current regulatory requirements and institutional frameworks in the United States. Our research questions exploring this tension were: Do practitioners perceive legal and institutional barriers to AM? If so, what are they? What are practitioners' perceptions regarding how AM methodologies are actually being implemented? The overarching hypothesis for our study was that many practitioners believe that current legal and institutional regimes for natural resource management in the United States do not adequately support the successful employment of AM procedures and protocols. 
Fig. 1. Diversity of respondents in terms of years of experience (A), geographic affiliation (B), organizational affiliation (C), and education level (D).

a.

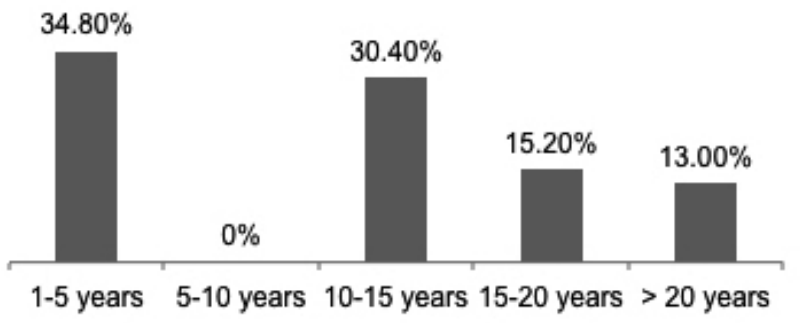

c.

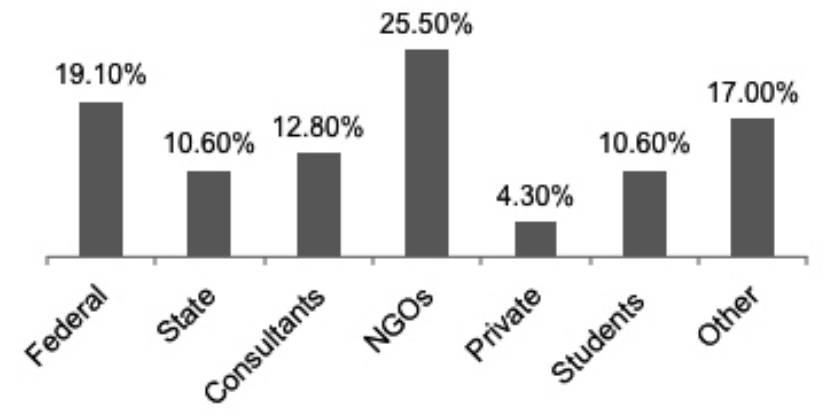

b.

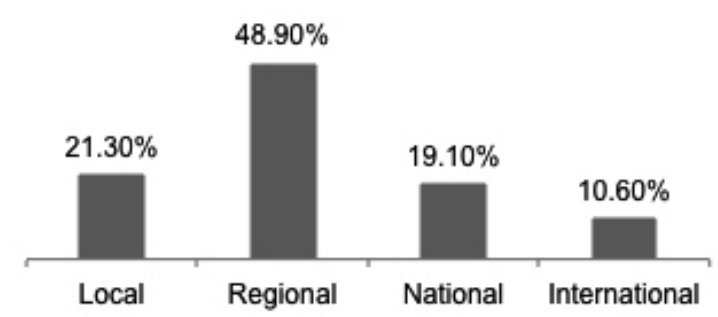

d.

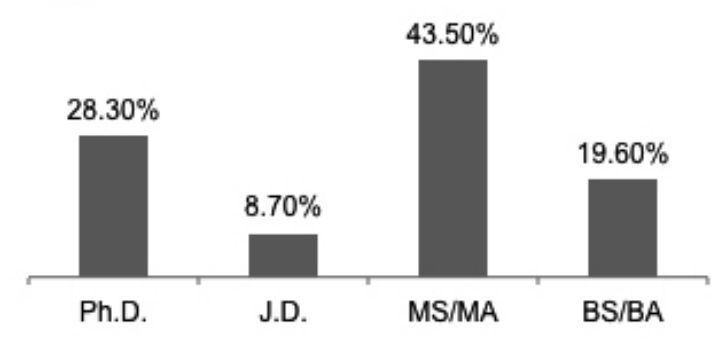

To test this hypothesis, we surveyed natural resource managers and other practitioners in the field who attended one or more Collaborative Adaptive Management Network (CAMNet) rendezvous from 2008 to 2011 (Appendix A). CAMNet is a nongovernmental organization formed in 2004 through a partnership between the Adaptive Management Practitioners Network and the Meridian Institute. This partnership was based on the belief that adaptive management and collaborative problem-solving are complementary tools and that often both are needed to address successfully complex natural resource management and restoration challenges. CAMNet fosters resolution of complex natural resource management problems through the practice of collaborative AM. We chose to survey CAMNet rendezvous participants as research subjects because they represent a cross-section of AM practitioners from a variety of professional roles and levels of experience (Figs. 1 and 2).

CAMNet's signature event is the Annual Rendezvous, which brings together practitioners from across the United States and beyond to share lessons learned and advance the practice of collaborative AM. The survey was sent via email to the 144 participants who attended a CAMNet Rendezvous during 2007-2011. Each year, CAMNet hosts a rendezvous at a site where AM is being practiced. The first rendezvous focused on Rocky Mountain National Park and was held in Estes Park, Colorado (14.9\% of respondents). The second meeting was in
Fig. 2. Diversity of respondents in terms of levels of experience with adaptive management.

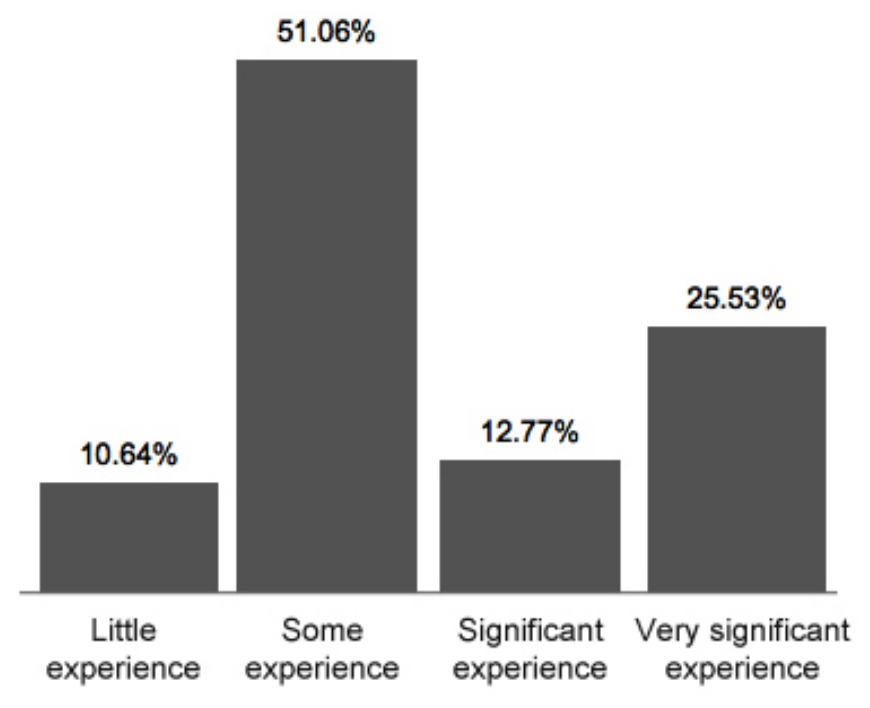

Homestead, Florida, in 2008 and focused on the Comprehensive Everglades Restoration Program (19.1\%). The 2009 rendezvous was held in Kearney, Nebraska, and highlighted AM efforts in the Platte River Recovery and 
Implementation Program (25.5\%). The 2010 rendezvous in Tucson, Arizona, highlighted the Las Ciénegas National Conservation Area Adaptive Management Strategy in Arizona (40.4\%). Finally, the 2011 meeting in Keene, New Hampshire, (29.8\%) feature a number of projects in the surrounding areas, including the Wildlands and Woodlands Initiative.

The electronic survey used enhances the anonymity of respondents (Hewson et al. 1996, Schmidt 1997). The survey design followed the electronic version of the "Total Design Method" of a four-wave mail survey (Dillman 2000). The survey questions solicited information regarding our research questions, following the methods of Mazmanian and Sabatier (1989), by asking respondents to indicate their perceptions on a rating scale from 0 ("very much agree") to 4 ("very much disagree"). Respondents were also provided the option to expand on their answer to each question in a narrative format. As noted by Butler and Koontz (2005), although perceptual data have been used in numerous policy studies, including those in natural resources, they are inherently subjective. The survey's reliability was enhanced to the greatest extent possible by carefully wording questions and assuring confidentiality of responses following Butler and Koontz's (2005) methods. Validity for the survey was enhanced through pre-testing with a small sample, soliciting feedback, and making minor adjustments to the survey format and wording based on the feedback. The collected data were analyzed using the statistical software SYSTAT 11. Specifically, a series of correlational analyses were used for quantitative analyses. The survey of 144 participants yielded 48 responses, which is an acceptable response rate (33.34\%) and an appropriate sample size for purposes of analysis.

\section{RESULTS}

The first section of the survey assessed the respondents' demographic information and their involvement with AM to determine whether we were able to reach a cross-section of AM practitioners from a variety of professional roles and level of experience. The survey results suggest that this was the case; the respondents demonstrated diversity in terms of their level of experience, years of experience, geographical expertise, professional affiliations, and level of education (Fig. 1). Most respondents reported that they had experience with AM implementation. The level of involvement was categorized into little (only attended the CAMNet rendezvous), some (I am involved in projects that use AM), significant (I use AM in the field), and very significant (I have professional training in AM methods and engage in AM on a regular basis; Fig. 2).

Our first research question investigates practitioners' perceptions of legal and institutional issues related to AM. We wanted to know whether practitioners felt hampered by legal and institutional constraints, and if they did, we wanted to know their suggestions for how to address and/or mitigate those constraints. We asked them seven questions along these lines. First, we asked respondents to evaluate the statement, "Laws and other administrative and regulatory requirements constrain efforts to engage in AM." Of those surveyed, the overwhelming majority (74.4\%) agreed. When asked to give an example, approximately the same number $(73.2 \%)$ stated that they could provide an example of specific legal requirements that hamper AM. Examples included the Endangered Species Act, the National Environmental Policy Act, the Magnuson Stevens Act, and the Marine Mammal Protection Act (Table 1). A related question asked specifically whether existing legal mandates make it difficult to engage in $\mathrm{AM}$ practices because they require specific management outcomes. Participants largely agreed with this statement, with $32.6 \%$ and $23.9 \%$ responding "somewhat agree" and "very much agree", respectively, and $23.9 \%$ responding "somewhat disagree", $8.7 \%$ "very much disagree", and 10.9\% "not sure".

Our next two questions related to potential conflicts between management priorities and the conditions that are required for AM to be successful (Salafsky et al. 2001). First, we asked practitioners to evaluate the statement, "In general, existing legal mandates place management objectives first and place secondary importance on gathering the necessary baseline information." Most of the respondents agreed with this statement, with $36.2 \%$ responding "somewhat agree" and $27.7 \%$ "very much agree". Interestingly, many of the respondents were "not sure" (23.4\%), and, although a few $(12.8 \%)$ selected "somewhat disagree", none selected "strongly disagree". Next, we asked whether they viewed management plans (such as Bureau of Land Management resource management plans) as having the flexibility necessary to engage in AM. There was a wide range of opinion on the issue of management plan flexibility; most of the respondents felt that the necessary flexibility does exist within management plans, with $37.5 \%$ responding "somewhat agree" and $18.8 \%$ "very much agree". However, a significant number of respondents also fell into the "somewhat disagree" $(20.8 \%)$ and "very much disagree" (14.6\%) categories.

The final two questions related to legal and institutional constraints focused on possibilities for reform. When asked whether changes could be made in existing legal requirements to make AM more successful, most respondents selected either "somewhat agree" $(25.5 \%)$ or "very much agree" (38.3\%). Several were "not sure" (21.3\%). When a follow-up question asked participants whether they could provide suggestions for specific changes to existing legal requirements that would facilitate $\mathrm{AM}$, over half of the participants provided comments (discussed below).

Our second research question investigated practitioners' perceptions regarding how effectively AM methodologies were actually put into practice in the field. While there is no one-size-fits-all approach for the application of AM, our survey reflects suggestions and approaches outlined by Salafsky et al. (2001) for AM implementation, which include 
Table 1. Specific examples of legal constraints provided by practitioners.

\begin{tabular}{|c|c|}
\hline Legal statute & Description of legal constraint \\
\hline \multirow[t]{4}{*}{ Endangered Species Act (ESA) } & • "ESA requirements to safeguard listed species." \\
\hline & $\begin{array}{l}\text { - "ESA may hamper adaptive management (AM) if a Biological Opinion issued under Section } 7 \text { consultation limits } \\
\text { flexible management. FACA [Federal Advisory Committee Act] issues may hamper stakeholder engagement in AM. } \\
\text { Often agency culture, policies, and manager/staff understanding and experience with AM are the most limiting." }\end{array}$ \\
\hline & • "ESA enforcement can foster AM, but it can also limit the ability to successfully implement AM." \\
\hline & $\begin{array}{l}\text { - "The Platte River Recovery Program is an exception, but that was developed specifically as mitigation for water } \\
\text { depletions to the Platte River, so that is a different situation. In a more normal habitat conservation plan or conservation } \\
\text { action for a listed species, there is typically little flexibility in the range of management options available for use due to } \\
\text { the fact that the species is federally listed and protected from 'take' by the ESA. This is not necessarily a bad thing, but } \\
\text { can hamper adaptive management." }\end{array}$ \\
\hline
\end{tabular}

• "Some interpret the ESA as being rigid. But I've seen managers and interest groups agree on a flexible approach."

- "Best example is ESA Section 7 determination of jeopardy or adverse modification of critical habitat that may limit the range of experiments that can be done to test outcomes of different management actions."

- "ESA mandates single species management. It is not always appropriate and often assumes that 'no action' is the best management, when that is rarely the case in the bigger picture, and often not for the species in question."

- "Candidate species for listing - a couple examples I can think of are species we know very little about but that have locally strong populations where we could try a couple different techniques to determine what habitat they require or do best in. But due to U.S. Fish and Wildlife Service hampering work in areas with these species, we are leaving them to hope for the best and not helping them in any way."

National Environmental Policy Act (NEPA)

Sustainable Fisheries Act/ Magnusson-Stevens Management Act

Water supply and management statutes
• "NEPA requirements to evaluate all actions."

- "I think NEPA could work with AM if people inserted all management scenario alternatives into the EIS [environmental impact statement] process up front ... but there are those who say that is challenging. I've yet to participate in a NEPA process as a land manager, so those naysayers may be right."

- "I've heard that AM can be constrained by NEPA. At the same time, there are many NEPA documents that bear very little resemblance to the actual implementation of the project or the outcomes. Nonetheless, because the original document was definitive, it is considered ok, even though it is not accurate. It often ignores the flexibility decision makers use daily."

• "For fisheries: goal of economic efficiency; species managed individually; no consideration of nonfishing impacts"

- "In fisheries, Magnusson-Stevens Management Act requires managers to assess on the basis of population estimates of single species throughout the range while most overfishing problems exist at local levels... so little info that relates to management problems ever gets collected."

• "Water quality constraints can prevent water quantity improvements."

• "Safe yield/firm yield determinations of public water supply may hamper adaptive management of watersheds."

- "For example, as relates to major water development projects in the United States, there are stakeholders who have much to gain and stakeholders with much to lose if there are any changes to the status quo; and modifications to existing management regimes are explicit in adaptive management. Usually, stakeholders have built powerful political backing and supporting/complementary legal and regulatory frameworks to be sure the status quo is maintainedwitness management of the Mississippi and Missouri rivers." 
• "Mandated management actions that don't consider what would be best for our natural resources."

- "Any project authorization that requires one defined end state or implementation method regardless of outcome or continuing utility (i.e., Highway, Civil Works, etc.) rarely acknowledge existing flexibility in management much less trying something new."

- "Planning documents (RMPs [resource management plans] or others) often have flexibility, but establish sideboards."

- "I could name many for any existing Adaptive Management program now in place, but am convinced that self-interest is a much greater problem."

- "Highest and best use requirements found in land use strategies."

gathering baseline data, developing a conceptual model of the system being managed, implementing a monitoring plan, analyzing the data, communicating results back to stakeholders, and using the results from monitoring to adapt and learn. We developed survey questions for each of these topics, emphasizing those elements that we felt would provide the most insight into how AM is actually being engaged. The first survey question related to stakeholder involvement and asked respondents to evaluate the statement, "In my experience, AM efforts involve efforts to engage stakeholders from all affected interests in the AM processes." The overwhelming majority of the respondents believed that relevant stakeholders are involved in AM efforts, with 51.1\% selecting "very much agree" and 28.9\% "somewhat agree".

The second set of questions related to the need to develop a conceptual model of the social and/or ecological system under adaptive management. We asked three questions along these lines, relating specifically to (1) whether managers take the necessary time to build a conceptual model of the management area before engaging in AM, (2) whether those models included both human and ecological systems, and (3) whether, in general, baseline information and/or data about the relevant system(s) are gathered before AM takes place. Respondents were split on the issue of whether the necessary time is taken to build a conceptual model of the management area before engaging in AM, with $17.0 \%$ selecting "very much disagree", 25.5\% "somewhat disagree", 38.3\% "somewhat agree", $8.5 \%$ "very much agree", and 10.6\% "not sure". On a more encouraging note, respondents generally agreed (31.1\% "somewhat agree" and 33.3\% "very much agree") that when conceptual models are developed, they tend to include both human and ecological systems. One element of building a conceptual model is the investment in gathering baseline data before engaging in AM. While a large number agreed (43.8\% "somewhat agree" and $22.9 \%$ "very much agree") with the statement that this actually takes place, many were also in disagreement (25.0\% "somewhat disagree" and 6.3\% "very much disagree").

With regard to monitoring, we asked two questions. First, we wanted to know whether practitioners felt that monitoring efforts were adequately funded. Their response was a strong no, with $53.2 \%$ selecting "strongly disagree" for the statement that monitoring efforts are adequately funded. An additional $19.1 \%$ selected "somewhat disagree", and only $17 \%$ "somewhat agree" that funding is adequate. None of the respondents selected "very much agree". When asked whether, once conducted, monitoring and assessment results are integrated into AM decision-making, the responses were slightly more positive, with $30.4 \%$ selecting "somewhat agree" and 23.9\% "very much agree". A strong number had the opinion that monitoring results were not actually incorporated back into decision-making (21.7\% "somewhat disagree", $15.2 \%$ "very much disagree").

Finally, we asked practitioners to evaluate the statement, "In my experience, when AM experiments tell us something new, management actions are changed to reflect what is learned." This question gets to the critical feedback loop required by AM. We wanted to know if, in practitioners' experiences, management decisions actually reflect the new knowledge created. On this issue, the respondents were fairly split: less than half perceived that learning was incorporated into management actions (41.3\% "somewhat agree", 2.2\% "very much agree"), and many perceived that learning was not incorporated (26.1\% "somewhat disagree", $13.0 \%$ "very much disagree"). Interestingly, a large number of respondents were "not sure" (17.4\%).

\section{DISCUSSION}

Our survey results provide some interesting insights into practitioners' perceptions of the legal requirements and institutional constraints that influence their work. Our results are based on the attitudes and opinions of a relatively 
Table 2. Summary of the Endangered Species Act (ESA) and its key provisions (Benson 2012).

\begin{tabular}{|c|c|}
\hline Provision & Description and enforceability \\
\hline $\begin{array}{l}\text { Policy mandate: } \\
\text { ESA Section } 2 \text { (16 U.S.C. } \S 1531)\end{array}$ & $\begin{array}{l}\text { The ESA has become a primary driver of many adaptive management efforts in the United States because of its } \\
\text { uncompromising position against biodiversity loss. Its overall policy is to provide "a means whereby the } \\
\text { ecosystems upon which endangered species and threatened species depend may be conserved, to provide a } \\
\text { program for the conservation of such endangered species and threatened species." As a result, it operationalizes } \\
\text { many key provisions that drive environmental protection. }\end{array}$ \\
\hline $\begin{array}{l}\text { Prohibition against take: } \\
\text { ESA Section } 3 \text { (16 U.S.C. } \S 1532 \text { ) }\end{array}$ & $\begin{array}{l}\text { The ESA protects endangered species from "take." Take is broadly defined to include any actions that harm the } \\
\text { species, including "habitat modification or degradation where it actually kills or injures wildlife by significantly } \\
\text { impairing essential behavior patterns, including breeding, feeding, or sheltering." }\end{array}$ \\
\hline Critical habitat designation: & Once a species is listed, the appropriate wildlife agency has 1 yr to determine its "critical habitat." Critical \\
\hline $\begin{array}{l}\text { ESA Sections } 3 \text { and } 4 \text { (16 U.S.C. } § 1532 \\
(5)(A), 1533(a)(3)(A))\end{array}$ & $\begin{array}{l}\text { habitat is defined as: (1) specific areas within the geographical area occupied by the species at the time of listing, } \\
\text { if they contain physical or biological features essential to conservation, and those features may require special } \\
\text { management considerations or protection; and (2) specific areas outside the geographical area occupied by the } \\
\text { species if the agency determines that the area itself is essential for conservation. Economic factors are considered } \\
\text { in the designation. Alteration of critical habitat triggers the consultation requirement. }\end{array}$ \\
\hline Consultation process: & The law requires all federal agencies to consult with the appropriate wildlife agency to ensure that their actions \\
\hline ESA Section 7 (16 U.S.C. $\$ 1536)$ & $\begin{array}{l}\text { are not likely to jeopardize the continued existence of listed species or result in destruction or adverse } \\
\text { modification of critical habitat. Engagement in consultation is legally enforceable. The consultation process } \\
\text { concludes with the wildlife agency issuing a Biological Opinion that includes appropriate measures that must be } \\
\text { taken to avoid "take," in addition to an incidental take permit. }\end{array}$ \\
\hline $\begin{array}{l}\text { Citizen enforcement mechanism: } \\
\text { ESA Section } 11 \text { (16 § U.S.C. } 1540(\mathrm{~g}) \text { ) }\end{array}$ & $\begin{array}{l}\text { Section } 11 \text { provides for civil and criminal penalties for ESA enforcement. Subsection (g) allows any citizen to } \\
\text { petition for listing of a species and/or compel the government to perform nondiscretionary duties under the law } \\
\text { (e.g., engage in consultation under Section 7). }\end{array}$ \\
\hline
\end{tabular}

sophisticated and experienced group with regard to their understanding of AM (Fig. 2). We were somewhat surprised to find that the survey results did not correlate well with any particular type of background or level of experience. Responses from federal agency participants, for example, did not differ significantly from those of private consultants, and responses from individuals with extensive experience with AM did not differ significantly from those with relatively little experience, etc. Based on this, we conclude that our survey results express opinions that are widely shared across various types of professional experience, current employment, and educational background.

The first observation to be made is that the survey results confirm our overarching hypothesis that practitioners feel hampered by legal and institutional constraints. Well over $70 \%$ of respondents believed that constraints existed, and many could specifically name one or more examples of a legal constraint on their implementation of AM (Table 1). Many of the narrative comments related to the Endangered Species Act (ESA; Table 2) and the National Environmental Policy Act (NEPA; Table 3).

Participants largely agreed that one current impediment to AM is that legal requirements often require specific management outcomes. Interestingly, however, their responses also indicated optimism with regard to the potential for improvement. Respondents' perceptions of existing legal barriers as constraints on AM were positively correlated such that those who reported that existing legal mandates make it difficult to engage in AM practices because they require specific management outcomes (Question 18) also reported that changes could be made in existing legal requirements to make AM more successful (Question 16; $R=0.550, P<0.05$; Fig. 3). Data were aggregated to "agree" and "disagree" for conceptualization: $76 \%$ of the respondents agreed that there are legal barriers, of which $56 \%$ of the respondents also agreed that such legal constraints could be changed. In other words, a significant number of respondents were hopeful that reforms could be put in place to improve conditions for AM implementation. These data reinforce the idea that, while specific management outcomes or directives (e.g., recovery of a specific species) are not an AM impediment per se, the challenge lies in accommodating a sometimes narrow management focus while also maintaining the necessarily flexibility to engage in AM.

A second observation relates to the correlation between current management priorities and opportunities for legal reform. When asking about potential conflicts between management priorities, flexibility, and other conditions necessary to support AM (e.g., baseline data collection) we found a range of opinion. Most of those who provided written comments in response to these issues noted that although flexibility might exist on paper, this does not always translate into flexibility in practice. For example, one respondent noted, "I think most management plans would allow for more flexibility than managers might recognize, particularly if managers work to increase 'social license' for flexible actions by developing shared goals with their public constituents." Again, however, there was a note of optimism. Respondents' perceptions of existing legal constraints (Question 18) were positively 
Table 3. Summary of the National Environmental Policy Act (NEPA) and its key provisions.

\begin{tabular}{|c|c|}
\hline Provision & Description \\
\hline $\begin{array}{l}\text { Overall policy: } \\
\text { (42 U.S.C. § 4332) }\end{array}$ & $\begin{array}{l}\text { Passed into law in 1970, the NEPA is one of the most influential environmental laws in the United } \\
\text { States. It requires all federal agencies that propose a "major federal action significantly affecting the } \\
\text { quality of the human environment" to first assess the potential impacts of the proposed action. }\end{array}$ \\
\hline $\begin{array}{l}\text { Environmental impact statement: } \\
42 \text { U.S.C. } \S 4332(1)(C)\end{array}$ & $\begin{array}{l}\text { All major federal actions require the development of an environmental impact statement (EIS) "that } \\
\text { informs both the agency and the public regarding possible environmental consequences. An EIS } \\
\text { generally comprises several elements, including: (i) the environmental impact of the proposed action, } \\
\text { (ii) any adverse environmental effects which cannot be avoided should the proposal be implemented, } \\
\text { (iii) alternatives to the proposed action, (iv) the relationship between local short-term uses, [the] } \\
\text { environment, and the maintenance and enhancement of long-term productivity, and (v) any irreversible } \\
\text { and irretrievable commitments of resources which would be involved in the proposed action should it } \\
\text { be implemented." }\end{array}$ \\
\hline $\begin{array}{l}42 \text { U.S.C. } \S 4332(1)(C) \text { : } \\
40 \text { CFR } 1502.9(c) . \text { Supplemental environmental } \\
\text { impact statement }\end{array}$ & $\begin{array}{l}\text { Additional NEPA analysis is required when significant new circumstances or information relevant to } \\
\text { environmental concerns or substantial changes in the proposed action that are relevant to } \\
\text { environmental concerns may necessitate the preparation of a supplemental EIS. Increasingly, the } \\
\text { supplemental NEPA process is becoming important to adaptive management efforts in order to } \\
\text { integrate new information back into the management process (Benson 2010a). }\end{array}$ \\
\hline
\end{tabular}

Fig. 3. Respondents' perceptions of existing legal barriers as constraints on adaptive management were positively correlated: Those who reported that existing legal mandates make it difficult to engage in adaptive management practices because they require specific management outcomes also reported that changes could be made in existing legal requirements to make adaptive management more successful $(R=0.550, P<0.05)$.

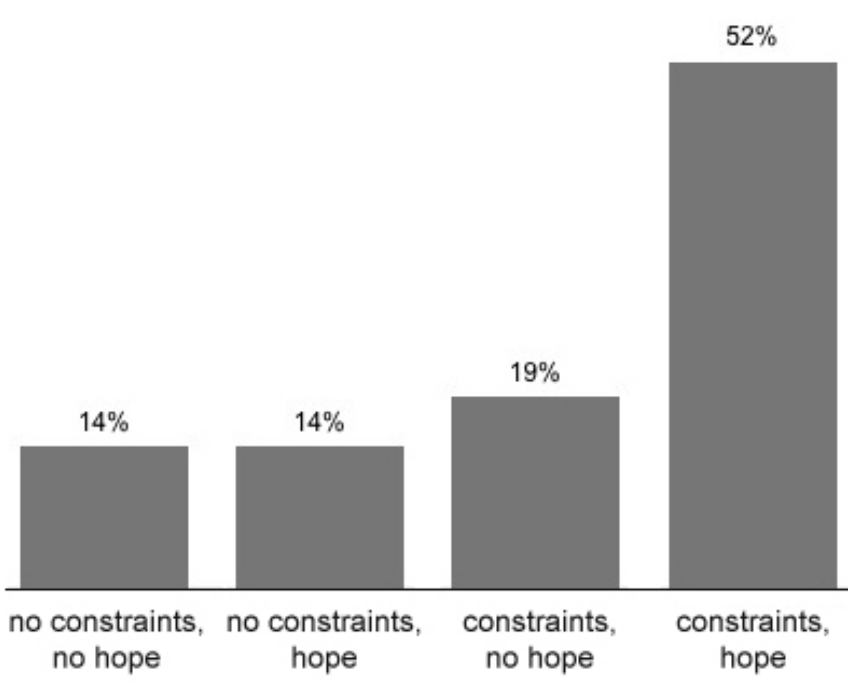

correlated such that those who reported that existing legal mandates place management objectives first and place secondary importance on gathering the necessary baseline information also reported that changes could be made in existing legal requirements to make AM more successful (Question 10; $R=0.425, P<0.05$; Fig. 4). Data were aggregated to "agree" and "disagree" for conceptualization:
$72 \%$ of the respondents agreed that there are existing legal constraints; of these, $53 \%$ also agreed that such legal constraints could be changed. In other words, there is a strong perception that legal reforms can be made to make AM more successful, and several respondents provided specific examples (Table 4). For the most part, however, their responses evidenced that many AM practitioners are frustrated with the status quo.

Fig. 4. Respondents' perceptions of existing legal constraints and expectations for changes were positively correlated: Those who reported that existing legal mandates place management objectives first and place secondary importance on gathering the necessary baseline information also reported that changes could be made in existing legal requirements to make adaptive management more successful $(R=0.425, P<0.05)$.

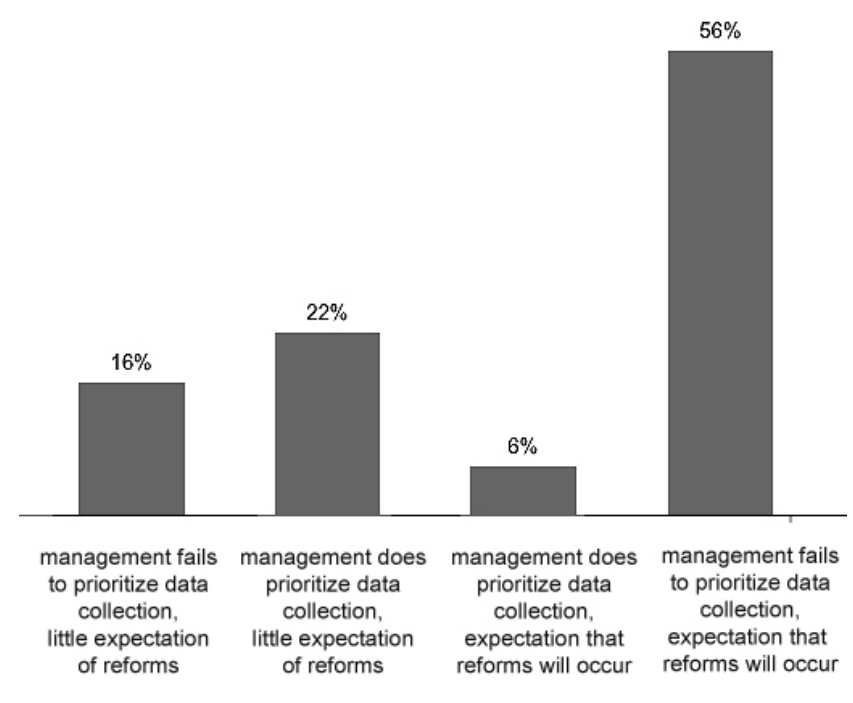


Table 4. Participants' responses to the question: Can you suggest specific changes to existing legal requirements that would facilitate adaptive management?

\begin{tabular}{ll}
\hline \hline Legal statute & Participant response \\
\hline $\begin{array}{l}\text { National Environmental Policy Act } \\
\text { (NEPA) }\end{array}$ & "NEPA reconfiguration." \\
& "Amend NEPA so that there is no confusion on how to insert multiple management scenarios into the environmental \\
assessment process." & • "Recent advocacy by the Council on Environmental Quality (CEQ) for inclusion of adaptive management (AM) into the \\
& NEPA cycle is a good first step; but it could be taken further to frame alternatives as competing hypotheses that would be \\
& tested through AM. This could make the NEPA cycle take longer, but would vastly improve alternative selection." \\
& • "There are examples of flexible and collaborative NEPA analyses. We do not have to wait until someone changes NEPA \\
& to make it work better. The CEQ has provided helpful guidance in this regard, and continues to work toward showcasing \\
better ways of incorporating collaboration and AM into NEPA. Ways of implementing NEPA differently include investing \\
more time at the beginning of a NEPA process to involve stakeholders in developing both goals and alternative actions-a \\
more collaborative process is likely to yield a wider range of alternatives and more social license for flexibility in actions, \\
more emphasis on goals and outcomes, and design of explicit processes for modifying actions to better achieve desired \\
outcomes."
\end{tabular}

Endangered Species Act (ESA)

Fisheries management

Congressional action/legal reforms
- "Review the ESA; AM insertion would strengthen that statute because so much uncertainty is wrapped up in threatened and endangered species conservation."

- "In particular, ESA-related judicial decisions and documents such as biological opinions should all have the same definition of AM, and if AM is required it should be a rigorous attempt at linking science to decision-making."

- "On the ESA side, the recent AM implementation plan for the Columbia River (FCRPS AMIP) is a very important step forward in allowing greater flexibility in conducting experiments while interjecting contingencies that provide protection for federally listed species."

• "Major laws such as section 7."

- "Moving away from single species requirements to whole ecosystem requirements. Recognize fisheries as part of the ecosystem and design how the fleet should look to be consistent with its particular regional ecosystem."

- "Have fisheries councils create management sub-units in their management area that are charged with the responsibility for designing a plan for their sub-unit using collaborative management methods. It should be staffed with representatives of all stakeholders to occur; fishers should be elected by their peers."

- "Look at limiting the liability of agencies from lawsuits from environmental groups. Look at how these environmental groups are interfering with the management of wolves in the northern Rockies. If the agencies have some shelter from lawsuits, they may approach their responsibilities for land management differently."

- "The appropriations process."

- "Authorizing legislation for a restoration program effort required AM; additional language in the legislation could potentially help to better define what the decision-making universe is to help define it for the managers that have to implement it. In other words, give the managers direction (and legal/political coverage) to have flexibility in management decisions to encourage them from something other than the status quo (almost always a 'safer' decision-making space for them)."

- "I believe that Congress could institute the requirement for an adaptive management approach into funding for the top 1012 largest landscape-level restoration efforts currently ongoing (i.e., Everglades, Gulf Coast, Missouri River, Great Lakes, etc.)."

- "Administrative Procedure Act needs to have an adaptive management track that frees government agencies from the need to go through full notice and comment for every adaptive change that they make in resource management."

- "I'm not supportive of making use of AM a legal requirement for several reasons. AM is not always the best approach for implementing management actions (e.g., AM is not needed when uncertainty is low and values are shared among stakeholders). AM should remain adaptive; there would be major issues in institutionalizing." 
The second set of observations relates to practitioners' perceptions regarding how well AM methodologies are actually being engaged in the field. Interestingly, it appears that several of the participants struggled with this distinction. The survey did not ask respondents what ought to happen but rather what they perceive is happening (based on their own experience), and several of the narrative comments to our questions suggested that the respondents wanted to respond in terms of theory rather than practice. For example when asked, "Please evaluate the following statement: Monitoring and assessment results are integrated into AM decisionmaking", we received narrative comments such as, "Perhaps 'should' should be used instead of 'are", and "When AM decision-making is done properly, yes." For this reason, we are a bit less certain how reliable these answers are. For purposes of this analysis, we are working from the assumption that respondents answered the question as it was presented to them rather than how they wished it to be worded or phrased.

In terms of stakeholder involvement, we were encouraged to find that an overwhelming majority of the respondents believed that relevant stakeholders were involved in the AM processes in which they were engaged. This is perhaps not surprising given that CAMNet's mission statement states that the organization "is dedicated to the proposition that AM that involves active stakeholder collaboration is the preferred paradigm for resolving many complex natural resource management problems" (Collaborative Adaptive Management Network, http://www.adaptivemanagement.net/about).

Related to the need to develop a conceptual model of the adaptively managed SES, we found that while most agreed that conceptual models tend to include both human and ecological systems, respondents were split on the issue of whether the necessary time is taken to build a conceptual model of the management area before engaging in AM. Respondents were also relatively split on the issue of whether conceptual models reflect an investment in gathering baseline data before engaging in AM. When looking at the responses related to conceptual modeling in combination, we found that $31 \%$ of the respondents indicated that all three elements are currently met (Questions 6, 7, and 10; Fig. 5). This indicates a need for more careful employment of AM methodologies in this regard, and perhaps a need for better AM training with regard to the use and utility of conceptual models.

Fig. 5. Respondents' perceptions of how many of the three criteria for conceptual model development are met in their current practices.

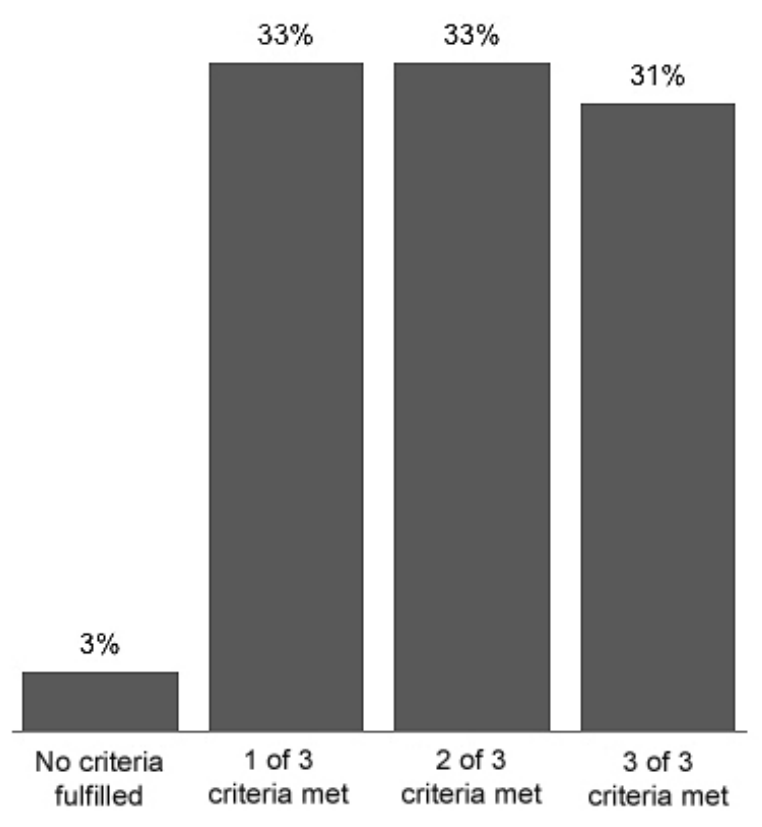

Perhaps the strongest response we received from the survey related to the need for adequate monitoring to implement AM 
Fig. 6. Respondents' perceptions of existing legal constraints and funding were negatively correlated: Those who reported that laws and other administrative and regulatory requirements constrain efforts to engage in adaptive management also reported that monitoring is not adequately funded for adaptive management efforts $(R=-0.460, P<0.05)$. Data was aggregated to "agree" and "disagree" for conceptualization.

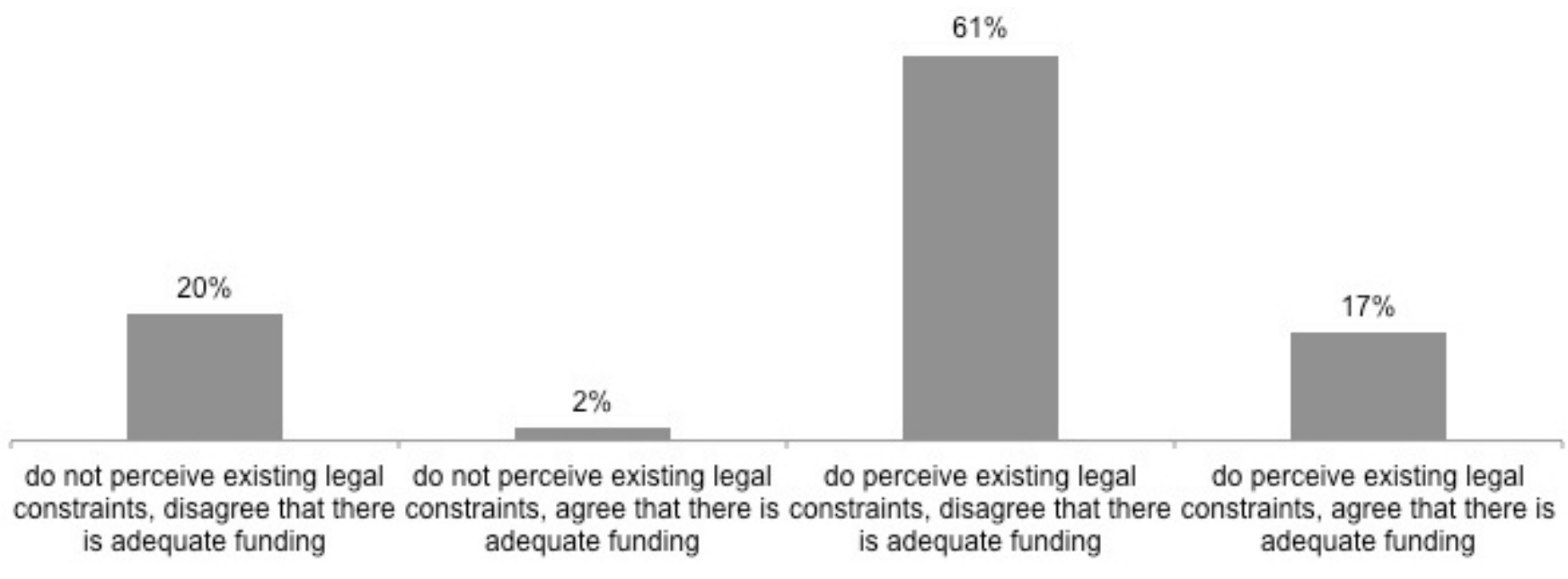

properly. Practitioners strongly feel that monitoring efforts related to AM are not adequately funded. They were slightly more positive with regard to the incorporation of monitoring and assessment results, but respondents were fairly split on the issue. Comments also indicated frustration with the quality of monitoring efforts. For example, one respondent noted, "Most monitoring I see is a half-way measure. It is expensive and inefficient, while not being controlled enough to have viable results... I see very little evidence that most monitoring is very useful in meeting its stated goal of informing the process."

Interestingly, but perhaps not surprisingly, respondents' perceptions of existing legal constraints (Question 18) were negatively correlated such that those who reported that laws and other administrative and regulatory requirements constrain efforts to engage in AM also reported that monitoring is not adequately funded for $\mathrm{AM}$ efforts (Question 13; $R$ $=-0.460, P<0.05)$. Data were aggregated to "agree" and "disagree" for conceptualization (Fig. 6): $78 \%$ of the respondents agreed there are existing legal constraints on AM; of these, $61 \%$ felt that monitoring is not adequately funded. While correlation does not necessarily indicate causation, this suggests that perhaps one of the most significant institutional barriers to effective AM implementation is adequate funding for monitoring. While we were curious about whether survey responses might correlate more strongly by rendezvous location (e.g., did practitioners in the Everglades feel more adequately funded than those in Tucson?), we did not find any statistically significant correlations between survey responses and rendezvous locations for any of the survey questions, indicating that this opinion is widely shared.

Finally, respondents were fairly split on the issue of whether new information gathered from monitoring was actually incorporated into decision-making, i.e., the critical feedback loop required by AM. Many of the narrative comments associated with this survey question emphasized the long lag time between knowledge and action: e.g., "perhaps eventually, but not in a timely manner" and "many times on big systems it takes a little while to get changes made". In sum, there is a fair amount of optimism among practitioners engaging in AM in the field. While practitioners agree that current legal and institutional constraints hamper AM efforts, particularly adequate funding to engage in necessary monitoring, they also believe that institutions will change to make AM more successful.

\section{CONCLUSIONS AND OPPORTUNTIES FOR FURTHER RESEARCH}

In the field, the actual practice of AM is often constrained and complicated by the legal and institutional regimes in which it takes place. The responses from practitioners reinforce the observations made by Ruhl and Fischman (2010:426) that what often occurs in practice is not true AM but what they call AM "lite," which they describe as "a watered-down version of the theory that resembles ad hoc contingency planning more than it does planned 'learning while doing'." Based on our practitioner survey and subsequent analysis, however, there are a number of observations to be made with regard to how AM implementation may be improved. First, many 
practitioners are frustrated with the current level of legal and institutional support for AM. They remain optimistic, however, and have several ideas for both general and specific improvements. The ESA and NEPA stand out as specific laws that warrant careful attention. For example, one practitioner suggested:

\section{Ways of implementing NEPA differently include investing more time at the beginning of a NEPA process to involve stakeholders in developing both goals and alternative actions. A more collaborative process is likely to yield a wider range of alternatives and more social license for flexibility in actions, more emphasis on goals and outcomes, and design of explicit processes for modifying actions to better achieve desired outcomes.}

This reflects suggestions made in relevant scholarship (e.g., Thrower 2006, Benson and Garmestani 2011), but is still not widely put into practice. Although the Council on Environmental Quality (CEQ; the main agency responsible for interpreting NEPA's requirements) commissioned a taskforce to provide recommendations for modernizing NEPA implementation along similar lines in 2003, it appears that practitioners perceive that there is still much room for improvement in the field.

In terms of the ESA, practitioners' experience the tension between management goals and legal/institutional flexibility. It is important to acknowledge that management goals and $\mathrm{AM}$ are not mutually exclusive. In fact, having goals is critical to successful AM. The problem arises when the goals themselves (here, the recovery of a specific species) narrow an agency's focus and limit management flexibility (Doremus 2002, Benson 2012). At the same time, species-driven situations are often in need of AM strategies. As one practitioner observed with regard to the ESA, "Insertion of adaptive management would strengthen that statute because so much uncertainty is wrapped up in threatened and endangered species conservation."

This closely relates to the second point involving the importance of developing a useful conceptual model of the SES being managed. Requiring a specific management outcome is not inherently incompatible with the importance of gathering the necessary baseline data. However, both the pace of decision-making and funding constraints can force agencies to design AM programs without sufficient data to develop a workable conceptual model. They can also constrain the degree to which practitioners are able to engage in experimentation. When experimentation does happen, adequate data collection and monitoring are essential. Monitoring is a key element that practitioners find to be lacking adequate institutional support. One practitioner explained, "The cost of monitoring is often one of the first parts of the budget to get cut when funds are limited." Most natural resource legal regimes, including NEPA, do not explicitly require monitoring (Benson and Garmestani 2011).

The absence of legal requirements for monitoring provides an example of the distinction between legal and institutional regimes. In the absence of an enforceable mandate, monitoring is vulnerable not only to budgetary constraints but also to protocol inconsistencies that limit the usefulness of the data. As one practitioner points out:

There is often a more fundamental problem [than]
that most monitoring is ineffective. Much of it is
research without replication, and unreplicated
studies are still often just bad science. One still
usually needs some sort of control factororyou have
no idea of that you are looking at. Often a few plots
done well is better. Most monitoring I see is a half-
way measure. It is expensive and inefficient, while
not being controlled enough to have viable results.
I suspect very often there should either be repeated
photo, or something bordering on a real experiment
with controls and replicates. Isee verylittle evidence
that most monitoring is very useful in meeting its
stated goal of informing the process.

Commitment for monitoring is essential and is a major area in which laws and institutions can improve (Sayre et al. 2013). The CEQ has provided a good first step related to the inclusion of AM into the NEPA cycle, but this could (as one practitioner suggested) be taken further to frame NEPA alternatives as competing hypotheses that would be tested through AM. The CEQ could also create a requirement for monitoring under NEPA and identify protocols and procedures that would assist $\mathrm{AM}$ and provide a basis for more consistent training in AM (Haugrud 2009).

Perhaps one of the most important changes needed is institutional support for experimentation that does not provide immediate successful outcomes and positive results. We appreciated one practitioner's simple suggestion that institutions need to "allow managers the opportunity to be wrong." Within the context in which most AM projects operate, continued funding and institutional and stakeholder support are often contingent on immediate results. However, AM takes time, and pressuring agencies and consultants to demonstrate "success" on a particular schedule or funding cycle makes it difficult to do AM well.

In General Design Principles for Resilience and Adaptive Capacity in Legal Systems: Applications to Climate Change Adaptation Law, J. B. Ruhl (2011) provides some suggestions for designing legal systems or climate change adaptation strategies that are broadly applicable to AM. Noting the extent to which this design effort will require a significant departure from the status quo, Ruhl (2011) emphasizes how the current legal system is preoccupied with certainty and finality and the 
difficulty that many federal agencies are having in incorporating AM. Ruhl (2011) focuses on strategies for building adaptive capacity within the legal system. He identifies the need to move away from the current level of front-end investment in NEPA and other processes that are inherently built on assumptions of predictability and to embrace strategies that include less emphasis on commandand-control and have more encouragement for collaborative, poly-centric, and adaptive models of governance.

While our research provides insight into practitioners' perceptions of AM implementation in the United States, it has also identified some potentially productive areas for further research. First, the survey of CAMNet rendezvous participants had the strength of cutting across many different project areas and institutional settings. At the same time, the result was a generalized set of perceptions, thereby limiting the capacity for identifying more specific observations and recommendations for legal and institutional reform. A more targeted survey would have the opportunity to provide a more refined analysis. The U.S. Bureau of Reclamation, for example, recently completed a review of 16 of its major river restoration programs, including the social and institutional aspects of restoration such as AM (U.S. Department of the Interior 2011). If we used our survey to gather data from participants directly involved in these efforts, the instrument could be designed to investigate specific legal and institutional issues specific to $U$. S. Bureau of Reclamation such as their funding mechanisms, monitoring protocols, NEPA guidance, etc.

Second, there is a need to investigate further the challenges and opportunities related to current approaches for integrating monitoring into AM implementation. Our research reveals that monitoring is perceived to be the weakest link in current efforts to engage successfully in AM. Further research directly related to monitoring could be directed toward identifying specific challenges, including funding mechanisms, to provide suggestions for reforms with the potential to improve AM implementation.

Responses to this article can be read online at: http://www.ecologyandsociety.org/issues/responses. $\mathrm{php/5613}$

\section{Acknowledgments:}

We thank the Collaborative Adaptive Management Network for its support in the design and publication of this research, Imogen Ainsworth for editorial assistance, and anonymous reviewers for helpful suggestions.

\section{LITERATURE CITED}

Allan, C., A. Curtis, G. Stankey, and B. Shindler. 2008. Adaptive management and watersheds: a social science perspective. Journal of the American Water Resources Association 44(1):166-174. http://dx.doi.org/10.1111/ j.1752-1688.2007.00145.x.

Angelo, M. J. 2009. Stumbling toward success: a story of adaptive law and ecological resilience. Nebraska Law Review 87(4):950-1007. [online] URL: http://digitalcommons.unl. edu/cgi/viewcontent.cgi article $=1046 \&$ context=nlr.

Benson, M. H. 2010a. Integrating adaptive management and oil and gas development: existing obstacles and opportunities for reform. Environmental Law Reporter 39(10):10962-10978.

Benson, M. H. 2010b. Adaptive management approaches by resource management agencies in the United States: implications for energy development in the Interior West. Journal of Energy and Natural Resources Law 28(1):87-118.

Benson, M. H. 2012. Intelligent tinkering: the Endangered Species Act and resilience. Ecology and Society 17(4): 28. http://dx.doi.org/10.5751/ES-05116-170428

Benson, M. H., and A. S. Garmestani. 2011. Embracing panarchy, building resilience and integrating adaptive management through a rebirth of the National Environmental Policy Act. Journal of Environmental Management 92 (5):1420-1427. http://dx.doi.org/10.1016/j.jenvman.2010.10.011

Berkes, F., and C. S. Seixas. 2005. Building resilience in lagoon social-ecological systems: a local-level perspective. Ecosystems 8(8):967-974. http://dx.doi.org/10.1007/ s10021-005-0140-4

Bodin, Ã., B. Crona, and H. Ernstson. 2006. Social networks in natural resource management: What is there to learn from a structural perspective? Ecology and Society 11(2): r2. [online] URL: http://www.ecologyandsociety.org/vol11/iss2/ resp2/.

Brugnach, M., A. Dewulf, C. Pahl-Wostl, and T. Taillieu. 2008. Toward a relational concept of uncertainty: about knowing too little, knowing too differently, and accepting not to know. Ecology and Society 13(2): 30. [online] URL: http:// www.ecologyandsociety.org/vol13/iss2/art30/.

Butler, K. F., and T. M. Koontz. 2005. Theory into practice: implementing ecosystem management objectives in the USDA Forest Service. Environmental Management 35 (2):138-150. http://dx.doi.org/10.1007/s00267-003-0312-y

Craig, R. K. 2010. "Stationarity is dead" - long live transformation: five principles for climate change adaptation law. Harvard Environmental Law Review 34(1):9-74. 
Dillman, D. A. 2000. Mail and internet surveys: the tailored design method. Volume 2. Wiley, New York, New York, USA.

Doremus, H. 2002. Adaptive management, the Endangered Species Act, and the institutional challenges of "new age" environmental protection. Washburn Law Journal 41 (1):50-89. [online] URL: http://contentdm.washburnlaw.edu/ utils/getfile/collection/wlj/id/5232/filename/5233.pdf.

Folke, C., T. Hahn, P. Olsson, and J. Norberg. 2005. Adaptive governance of social-ecological systems. Annual Review of Environment and Resources 30:441-473. http://dx.doi. org/10.1146/annurev.energy.30.050504.144511

Folke, C., L. Pritchard, Jr., F. Berkes, J. Colding, and U. Svedin. 2007. The problem of fit between ecosystems and institutions: ten years later. Ecology and Society 12(1): 30. [online] URL: http://www.ecologyandsociety.org/vol12/iss1/ art30/.

Grumbine, R. E. 1994. What is ecosystem management? Conservation Biology 8(1):27-38. http://dx.doi.org/10.1046/ j.1523-1739.1994.08010027.x

Gunderson, L., and C. S. Holling, editors. 2002. Panarchy: understanding transformations in human and natural systems. Island Press, Washington, D.C., USA.

Gunderson, L., and S. S. Light. 2006. Adaptive management and adaptive governance in the Everglades ecosystem. Policy Sciences 39(4):323-334. http://dx.doi.org/10.1007/s11077-006-9027-2

Haugrud, K. J. 2009. Perspectives on NEPA: Let's bring a bit of substance to NEPA by making mitigation mandatory. Environmental Law Reporter 39(7):10638-10639.

Hewson, C. M., D. Laurent, and C. M. Vogel. 1996. Proper methodologies for psychological and sociological studies conducted via the Internet. Behavior Research Methods, Instruments, and Computers 28(2):186-191. http://dx.doi. org/10.3758/BF03204763

Houck, O. A. 2009. Nature or nurture: what's wrong and what's right with adaptive management. Environmental Law Reporter 39(10):10923-10924.

Jacobson, S. K., J. K. Morris, J. S. Sanders, E. N. Wiley, M. Brooks, R. E. Bennetts, H. F. Percival, and S. Marynowski. 2006. Understanding barriers to implementation of an adaptive land management program. Conservation Biology 20 (5):1516-1527. http://dx.doi.org/10.1111/j.1523-1739.2006.00476. $\underline{\mathrm{X}}$

Karkkainen, B. C. 2004. Whither NEPA? New York University Environmental Law Journal 12(2):333-363. [online] URL: http://www1.law.nyu.edu/journals/envtllaw/issues/vol12/karkkainenfor\%20web.pdf.
King, J., and C. Brown 2006. Environmental flows: striking the balance between development and resource protection. Ecology and Society 11(2): 26. [online] URL: http://www. ecologyandsociety.org/vol11/iss2/art26/.

Lee, K. N. 1999. Appraising adaptive management. Ecology and Society 3(2): 3. [online] URL: http://www. ecologyandsociety.org/vol3/iss2/art3/.

Mazmanian, D. A., and P. A. Sabatier. 1989. Implementation and public policy: with a new postscript. University Press of America, Lanham, Maryland, USA.

McCarthy, M. A., and H. P. Possingham. 2007. Active adaptive management for conservation. Conservation Biology 21(4):956-963. http://dx.doi.org/10.1111/j.1523-1739.2007.00677. $\underline{\mathrm{X}}$

Moir, W. H., and W. M. Block. 2001. Adaptive management on public lands in the United States: commitment or rhetoric? Environmental Management 28(2):141-148. http://dx.doi. org/10.1007/s002670010213

Nie, M. 2008. The underappreciated role of regulatory enforcement in natural resource conservation. Policy Sciences 41(2):139-164. http://dx.doi.org/10.1007/s11077-008-9060-4

Nie, M. A., and C. A. Schultz. 2012. Decision-making triggers in adaptive management. Conservation Biology 26 (6):1137-1144.

Pahl-Wostl, C. 2007. The implications of complexity for integrated resources management. Environmental Modelling and Software 22(5):561-569. http://dx.doi.org/10.1016/j. envsoft.2005.12.024

Pahl-Wostl, C., J. Sendzimir, P. Jeffrey, J. Aerts, G. Berkamp, and K. Cross. 2007. Managing change toward adaptive water management through social learning. Ecology and Society 12 (2): 30. [online] URL: http://www.ecologyandsociety.org/ vol12/iss $2 / \operatorname{art} 30 /$.

Raadgever, G. T., E. Mostert, N. Kranz, E. Interwies, and J. G. Timmerman. 2008. Assessing management regimes in transboundary river basins: Do they support adaptive management? Ecology and Society 13(1): 14. [online] URL: http://www.ecologyandsociety.org/vol13/iss1/art14/.

Ruhl, J. B. 2005. Regulation by adaptive management-Is it possible? Minnesota Journal of Law, Science and Technology 7:21-57. [online] URL: http://mjlst.umn.edu/prod/groups/ ahc/@pub/@ahc/@mjlst/documents/asset/ahc asset 365948. pdf.

Ruhl, J. B. 2008. Adaptive management for natural resources — inevitable, impossible, or both? Rocky Mountain Mineral Law Institute 54: 11. 
Ruhl, J. B. 2011. General design principles for resilience and adaptive capacity in legal systems - with applications to climate change adaptation. North Carolina Law Review 89 (5):1373-1401.

Ruhl, J. B., and R. L. Fischman. 2010. Adaptive management in the Courts. Minnesota Law Review 95:424-484. [online] URL: http://www.minnesotalawreview.org/wp-content/ uploads/2011/07/Ruhl-Fischman MLR.pdf.

Salafsky, N., R. Margoluis, and K. Redford. 2001. Adaptive management: a tool for conservation practitioners. Biodiversity Support Program, Washington, D.C., USA. [online] URL: http://www.fosonline.org/resource/am-tool.

Salafsky, N., R. Margoluis, K. H. Redford, and J. G. Robinson. 2002. Improving the practice of conservation: a conceptual framework and research agenda for conservation science. Conservation Biology 16(6):1469-1479. http://dx.doi. org/10.1046/j.1523-1739.2002.01232.x

Sayre, N. F., E. Biber, and G. Marchesi. 2013. Social and legal effects on monitoring and adaptive management: a case study of National Forest grazing allotments, 1927-2007. Society \& Natural Resources 26(1):86-94. http://dx.doi.org/10.1080/0$\underline{8941920.2012 .694579}$

Schmidt, W. C. 1997. World-Wide Web survey research: benefits, potential problems, and solutions. Behavior Research Methods, Instruments and Computers 29(2):274-279. http:// dx.doi.org/10.3758/BF03204826

Stankey, G. H., B. T. Bormann, C. Ryan, B. Shindler, V. Sturtevant, R. N. Clark, and C. Philpot. 2003. Adaptive management and the Northwest Forest Plan: rhetoric and reality. Journal of Forestry 101(1):40-46.

Stringer, L. C., A. J. Dougill, E. Fraser, K. Hubacek, C. Prell, and M. S. Reed. 2006. Unpacking "participation" in the adaptive management of social-ecological systems: a critical review. Ecology and Society 11(2): 39. [online] URL: http:// www.ecologyandsociety.org/vol11/iss2/art39/.

Susskind, L., A. E. Camacho, and T. Schenk. 2010. Collaborative planning and adaptive management in Glen Canyon: a cautionary tale. Columbia Journal of Environmental Law 35:1-54. [online] URL: http:// columbiaenvironmentallaw.org/assets/pdfs/35.1/Susskind 35.1. pdf.

Thrower, J. 2006. Adaptive management and NEPA: how a nonequilibrium view of ecosystems mandates flexible regulation. Ecology Law Quarterly 33:871-895.

U.S. Army Corps of Engineers. 2002. Guidance on compensatory mitigation projects for aquatic resource impacts under the Corps Regulatory Program pursuant to Section 404 of the Clean Water Act and Section 10 of the Rivers and Harbors Act of 1899. U.S. Army Corps of Engineers,
Washington, D.C., USA. [online] URL: http://www.fws.gov/ habitatconservation/RGL2-02.pdf.

U.S. Department of the Interior. 2011. Bureau of Reclamation river restoration programs: a summary of 16 programs and shared institutional challenges. U.S. Department of the Interior, Denver, Colorado, USA. [online] URL: http:// uttoncenter.unm.edu/pdfs/USBR-Riv-Rest-Smry.pdf.

Walters, C. J. 2002. Adaptive management of renewable resources. Blackburn, Caldwell, New Jersey, USA.

Williams, B. K., R. C. Szaro, and C. D. Shapiro. 2009. Adaptive management: the U.S. Department of the Interior technical guide. U.S. Department of the Interior, Washington, D.C., USA. [online] URL: http://www.doi.gov/initiatives/

AdaptiveManagement/TechGuide.pdf.

Zellmer, S., and L. Gunderson. 2008. Why resilience may not always be a good thing: lessons in ecosystem restoration from Glen Canyon and the Everglades. Nebraska Law Review 87 (4):893-949. [online] URL: http://digitalcommons.unl.edu/ cgi/viewcontent.cgi? article $=1045 \&$ context=nlr. 
Appendix 1. Survey Instrument

Dear Adaptive Management Practitioner:

We are contacting you because we are conducting a survey of natural resources managers and others regarding how the concept of "adaptive management" is being integrated into natural resource decision-making in the United States. You are being contacted because you participated in one or more Collaborative Adaptive Management (CAMNet) rendezvous between 2007 and 2011.

As part of our research, we are requesting that you participate in a brief online survey about adaptive management. The survey should only take about 10-15 minutes to complete. Your involvement is voluntary, and you may choose not to participate.

Further, you can refuse to answer any of the questions at any time. There are no names or other identifying information like phone numbers, street addresses, or social security numbers associated with this survey. All responses will be kept confidential and aggregated for a statistical analysis and write-up. All survey responses will be kept for one year in a locked filing cabinet and/or on a password-protected computer at the University of New Mexico and then destroyed.

Your feedback is essential to this research. Findings from this research will provide information on how to better integrate adaptive management into natural resources decision-making and will assist CAMNet in their work to better inform and educate natural resource managers and others regarding adaptive management implementation.

If you have any questions about this research project, please feel free to email me at mhbenson@unm.edu. If you have questions regarding your legal rights as a research subject, you may call the UNM Human Research Protections Office at (505) 272-1129.

By completing this survey, you will be agreeing to participate in the above described research study.

Thank you for your time and consideration.

Sincerely,

Melinda Harm Benson

University of New Mexico

Department of Geography

Asa B. Stone

Central New Mexico Community College

Communication, Humanities \& Social Sciences Department 


\section{Please describe your level of experience with adaptive management.}

\section{There are many definitions of adaptive management being used by naturalresource managers, and below a couple of examples. How would you describe your own definition?}

National Research Council Definition (from National Research Council. 2004.

Adaptive management [is a decision process that] promotes flexible decision making that can be adjusted in the face of uncertainties as outcomes from management actions and other events become better understood. Careful monitoring of these outcomes both advances scientific understanding and helps adjust policies or operations as part of an iterative learning process. Adaptive management also recognizes the importance of natural variability in contributing to ecological resilience and productivity. It is not a 'trial and error' process, but rather emphasizes learning while doing. Adaptive management does not represent an end in itself, but rather a means to more effective decisions and enhanced benefits. Its true measure is in how well it helps meet environmental, social, and economic goals, increases scientific knowledge, and reduces tensions among stakeholders.

Foundations of Success definition (from Salafsky, Nick, Richard Margoluis, and Kent Redford. 2001. Adaptive Management: A Tool for Conservation Practitioners. Washington, D.C.: Biodiversity Support Program.Adaptive Management).

Adaptive management incorporates research into conservation action. Specifically, it is the integration of design, management, and monitoring to systematically test assumptions in order to adapt and learn. This definition can be expanded as follows: a) Testing assumptions is about systematically trying different actions to achieve a desired outcome. It is not, however, a random trial-and-error process. Instead, it involves first thinking about the situation at your project site, developing a specific set of assumptions about what is occurring and what actions you might be able to use to affect these events. You then implement these actions and monitor the actual results to see how they compare to the ones predicted by your assumptions. The key here is to develop an understanding of not only which actions work and which do not, but also why. b) Adaptation is about taking action to improve your project based on the results of your monitoring. If your project's actions did not 
achieve the expected results, it is because either your assumptions were wrong, your actions were poorly executed, the conditions at the project site have changed, your monitoring was faulty - or some combination of these problems. Adaptation involves changing your assumptions and your interventions to respond to the new information obtained through monitoring efforts. c) Learning is about systematically documenting the process that your team has gone through and the results you have achieved. This documentation will help your team avoid making the same mistakes in the future. Furthermore, it will enable other people in the broader conservation community to benefit from your experiences. Other practitioners are eager to learn from your successes and failures so that they can design and manage better projects and avoid some of the hazards and perils you may have encountered. By sharing the information that you have learned from your project, you will help conservation efforts around the world. Our definition of adaptive management includes a framework of specific conditions that warrant an adaptive management approach, steps for the process of adaptive management, and principles for the practice of adaptive management.

Defining Collaborative Adaptive Management (CAMNet Core Advisory Group, February 2010).

Adaptive management is a systematic management paradigm that assumes natural resource management policies and actions are not static, but are adjusted based on the combination of new scientific and socio-economic information. Management is improved through learning from actions taken on the ecosystems being affected. A collaborative adaptive management approach incorporates and links knowledge and credible science with the experience and values of stakeholders and managers for more effective management decision-making. Public participation in reviewing a program drafted by others is not collaborative adaptive management. Given the inherent ecological and social uncertainty in complex resource management decision- making, adaptive management recognizes that it is not always possible, a priori, to identify the "best" management alternative. Therefore, an experimental approach is warranted, and learning about the system becomes a deliberate goal similar to traditional ecological, economic, or social goals. Integral parts of adaptive management. Since adaptive management is often implemented in complex ecological and social settings, a collaborative process - in which multiple stakeholders participate in learning and developing a shared understanding about management goals, objectives, and decisions is an essential element of success. Stakeholder collaboration helps inform decision-making, build support for effective implementation, address disputes and enhances the likelihood of sustainable solutions. CAMNet experience 
suggests that collaborative adaptive management is best suited for situations where there are questions about the best management approach; opportunities to test lower-level risk, reversible management options; and reasonable decision space. Facilitating appropriate use of collaborative adaptive management also means recognizing when it is not the right approach. Adaptive management is not feasible where alternative outcomes cannot be identified or are not possible. A collaborative approach is not necessary when only one landowner is involved, and may not be necessary if there is agreement about the management action to be taken

\section{Please evaluate the following statement: I am often involved in collaborative multi-stakeholder processes involving adaptive management.}

Please evaluate the following statement: I am often involved in collaborative multistakeholder processes involving adaptive management. 1. Very much disagree

2. Somewhat disagree

3. Somewhat agree

4. Very much agree

N. Not sure

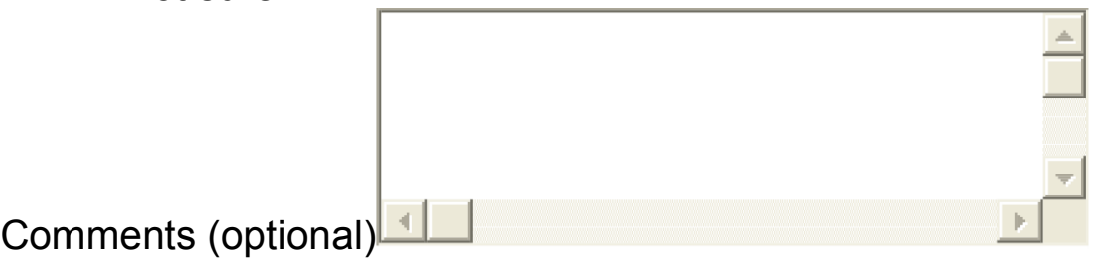

\section{Please evaluate the following statement: A central component of my} job is the implementation of adaptive management.

Please evaluate the following statement: A central component of my job is the implementation of adaptive management. 1. Very much disagree

2. Somewhat disagree

3. Somewhat agree

4. Very much agree

N. Not sure 
Comments (optional) $1 \square$

5. Please evaluate the following statement: In my experience adaptive management efforts often involve collaborations between agencies.

Please evaluate the following statement: In my experience adaptive management efforts often involve collaborations between agencies. 1. Very much disagree

2. Somewhat disagree

3. Somewhat agree

4. Very much agree

N. Not sure

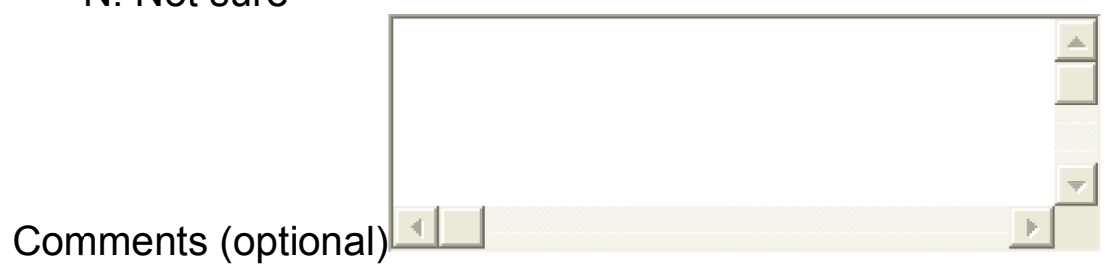

6. Please evaluate the following statement: Managers usually take the time to build a conceptual model of the management area before engaging in adaptive management.

Please evaluate the following statement: Managers usually take the time to build a conceptual model of the management area before engaging in adaptive management. 1. Very much disagree

2. Somewhat disagree

3. Somewhat agree

4. Very much agree

N. Not sure

Comments (optional) $1 \square$ 
7. Please evaluate the following statement: Conceptual models that are developed include both human and ecological systems.

Please evaluate the following statement: Conceptual models that are developed include both human and ecological systems. 1. Very much disagree

2. Somewhat disagree

3. Somewhat agree

4. Very much agree

N. Not sure

Comments (optional)

8. Please evaluate the following statement: In general, baseline information and/or data about the relevant system(s) are gathered before adaptive management takes place.

Please evaluate the following statement: In general, baseline information and/or data about the relevant system(s) are gathered before adaptive management takes place. 1. Very much disagree

2. Somewhat disagree

3. Somewhat agree

4. Very much agree

N. Not sure

Comments (optional)

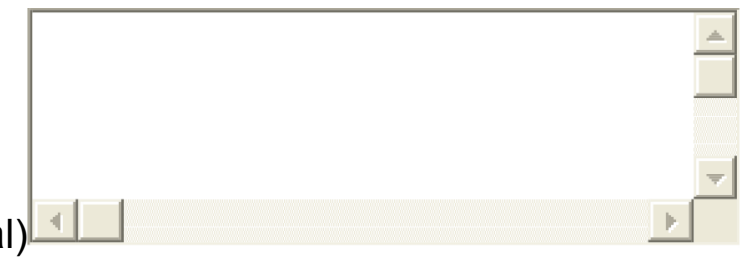

9. Please evaluate the following statement: In my experience, adaptive management efforts involve efforts to engage stakeholders from all affected interests in the adaptive management processes.

Please evaluate the following statement: In my experience, adaptive management efforts involve efforts to engage stakeholders from all affected interests in the adaptive management processes. 1. Very much disagree 
2. Somewhat disagree

3. Somewhat agree

4. Very much agree

N. Not sure

Comments (optional) $1+$

10. Please evaluate the following statement: In general, existing legal mandates place management objectives first and place secondary importance on gathering the necessary baseline information.

Please evaluate the following statement: In general, existing legal mandates place management objectives first and place secondary importance on gathering the necessary baseline information. 1 . Very much disagree

2. Somewhat disagree

3. Somewhat agree

4. Very much agree

N. Not sure

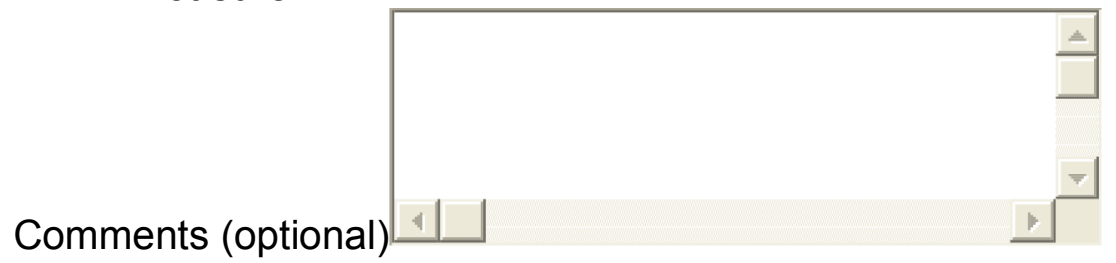


11. Please evaluate the following statement: In my experience, broad management plans (e.g., resource management plans) include the flexibility necessary to engage in adaptive management.

Please evaluate the following statement: In my experience, broad management plans (e.g., resource management plans) include the flexibility necessary to engage in adaptive management. 1 . Very much disagree

2. Somewhat disagree

3. Somewhat agree

4. Very much agree

N. Not sure

Please enter any comments or examples you would like to share here (optional)

12. Please evaluate the following statement: Laws and other administrative and regulatory requirements constrain efforts to engage in adaptive management.

Please evaluate the following statement: Laws and other administrative and regulatory requirements constrain efforts to engage in adaptive management. 1. Very much disagree

2. Somewhat disagree

3. Somewhat agree

4. Very much agree

N. Not sure

Comments (optional)

13. Regarding the question above (Q12), can you list any specific legal requirements that you believe hamper or facilitate adaptive management? Please explain. 
Regarding the question above (Q12), can you list any specific legal requirements that you believe hamper or facilitate adaptive management? Please explain. Yes

S No

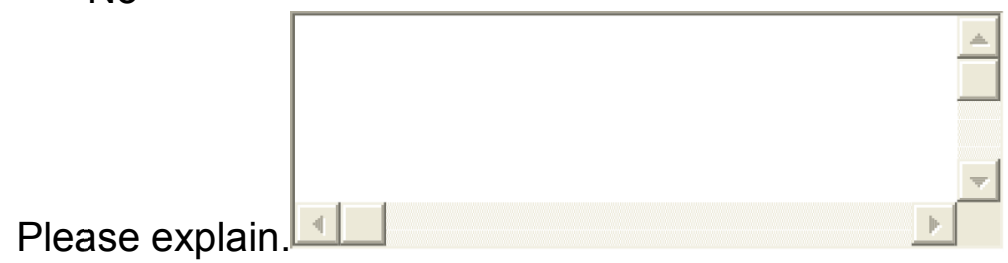

14. Please evaluate the following statement: Monitoring is adequately funded for adaptive management efforts.

Please evaluate the following statement: Monitoring is adequately funded for adaptive management efforts. 1. Very much disagree

2. Somewhat disagree

3. Somewhat agree

4. Very much agree

N. Not sure

Comments (optional) 1

15. Please evaluate the following statement: Monitoring and assessment results are integrated into adaptive management decision-making.

Please evaluate the following statement: Monitoring and assessment results are integrated into adaptive management decision-making. 1. Very much disagree

2. Somewhat disagree

3. Somewhat agree

4. Very much agree

N. Not sure

Please enter any comments or example you would like to share here (optional) 


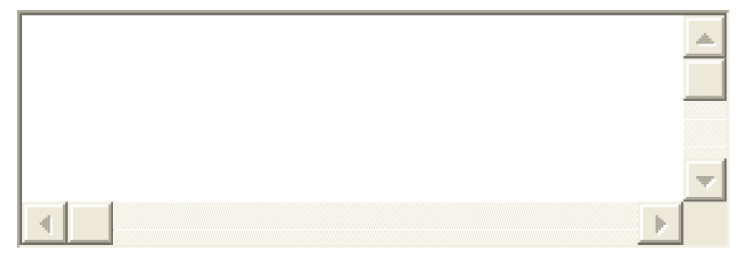

16. Please evaluate the following statement: I believe that changes could be made in existing legal requirements to make adaptive management more successful.

Please evaluate the following statement: I believe that changes could be made in existing legal requirements to make adaptive management more successful. 1. Very much disagree

2. Somewhat disagree

3. Somewhat agree

4. Very much agree

N. Not sure

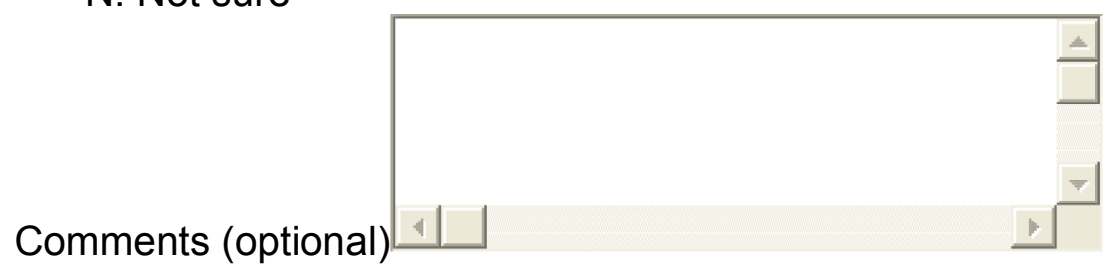

17. Regarding the question above (Q16), can you suggest specific changes to existing legal requirements that would facilitate adaptive management? Please explain.

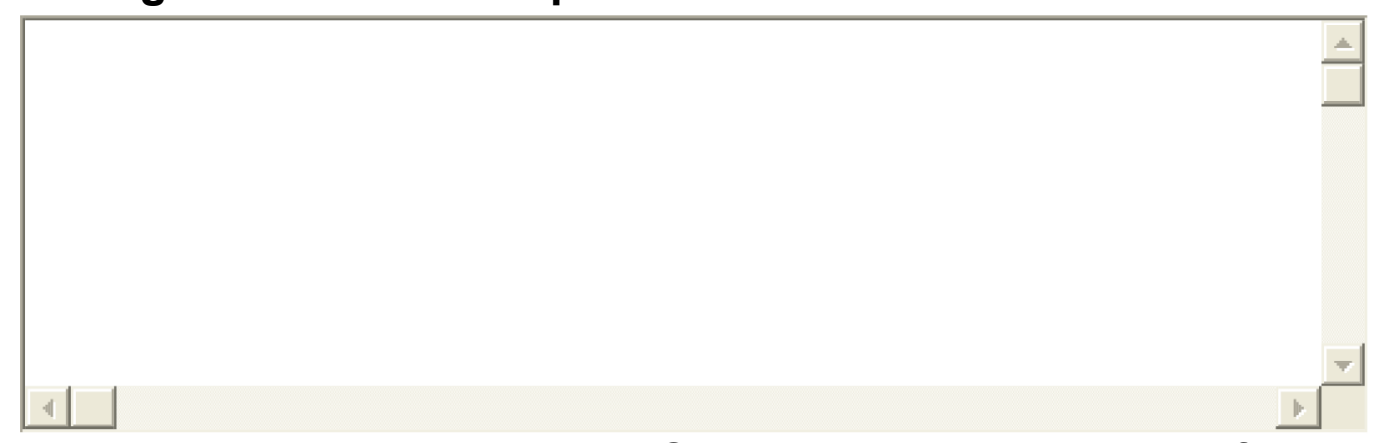

Regarding the question above (Q16), can you suggest specific changes to existing legal requirements that would facilitate adaptive management? Please explain. 
18. Please evaluate the following statement: In many cases, existing legal mandates (e.g., endangered species protection) make it difficult to engage in adaptive management practices because they require specific management outcomes.

Please evaluate the following statement: In many cases, existing legal mandates (e.g., endangered species protection) make it difficult to engage in adaptive management practices because they require specific management outcomes. 1 . Very much disagree

2. Somewhat disagree

3. Somewhat agree

4. Very much agree

N. Not sure

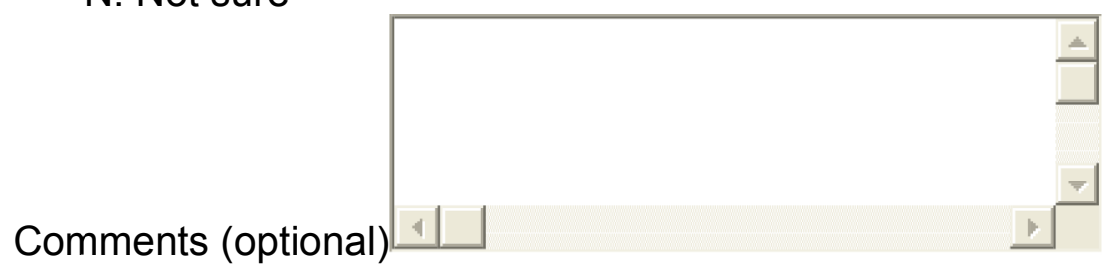

19. Please evaluate the following statement: It is important to communicate the results of adaptive management experiments to stakeholders.

Please evaluate the following statement: It is important to communicate the results of adaptive management experiments to stakeholders. 1. Very much disagree

2. Somewhat disagree

3. Somewhat agree

4. Very much agree

N. Not sure

Please enter any comments or example you would like to share here (optional) 
20. Please evaluate the following statement: In my experience, when adaptive management experiments tell us something new, management actions are changed to reflect what is learned.

Please evaluate the following statement: In my experience, when adaptive management experiments tell us something new, management actions are changed to reflect what is learned. 1. Very much disagree

2. Somewhat disagree

3. Somewhat agree

4. Very much agree

N. Not sure

Comments (optional)

21. Please provide any additional feedback information here.

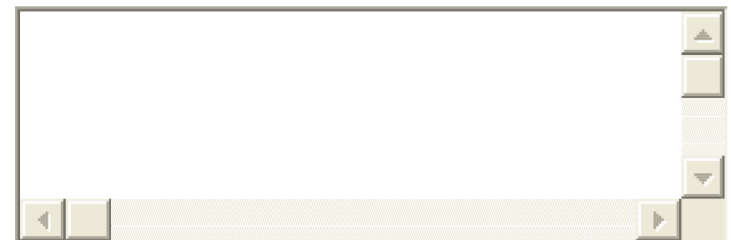

Please provide any additional feedback information here.

22. Please select your highest level of education.

Please select your highest level of education.

23. Please select the professional designation that best describes your current status.

Please select the professional designation that best describes your current status.

Please enter a comment (optional). 
24. How many years of experience do you have with regard to adaptive management?

How many years of experience do you have with regard to adaptive management?

25. Which CAMNet's annual rendezvous did you attend? (Please check all that apply.)

Which CAMNet's annual rendezvous did you attend? (Please check all that apply.) 2007 Estes Park, Colorado

Г 2008 Homestead, Florida

$\ulcorner 2009$ Kearney, Nebraska

$\ulcorner 2010$ Tucson, Arizona

$\ulcorner 2011$ Keene, New Hampshire

$\ulcorner$ Other (please specify)

26. How would you geographically describe your adaptive management experience?

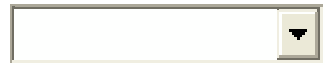

How would you geographically describe your adaptive management experience?

If appropriate, please elaborate.

Thank you for your participation! 